LBNL 51099

\title{
Longevity of Duct Tape in Residential Air Distribution Systems: 1-D, 2-D, and 3-D Joints
}

\author{
Bass Abushakra \\ Energy Performance of Buildings Group \\ Indoor Environment Department \\ Lawrence Berkeley National Laboratory \\ One Cyclotron Road \\ Berkeley, CA 94720
}

December 2002

This work was supported by the California Energy Commission through the Public Interest Energy Research program under contract no. 500-98-033, and by the Assistant Secretary for Energy Efficiency and Renewable Energy, Office of Building Technology, State and Community Programs, Office of Building Research and Standards, of the U.S. Department of Energy under contract no. DE-AC03-76SF00098. 


\section{Executive Summary}

This report summarizes the results of two high temperature longevity tests conducted by the Energy Performance of Building Group (EPB). The first test involved the aging of common "core-to-collar joints" of flexible duct to sheet metal collars, and sheet metal "collar-to-plenum joints" exposed to continuous $200^{\circ} \mathrm{F}\left(93^{\circ} \mathrm{C}\right)$ circulating air. The second test consisted of baking duct tape specimens in a constant $212^{\circ} \mathrm{F}\left(100^{\circ} \mathrm{C}\right)$ oven following the UL 181B-FX "Temperature Test" (Underwriters Laboratory 1995) requirements. The longevity of the sheet metal collar-to-plenum joints was tested based on the $10 \%$ of unsealed joint leakage criteria (established in previous work (Walker et al. 1998 and 1999, Walker and Sherman 1998, and Sherman et al. 2000)). Since an unsealed flexible duct joint can have a variable leakage depending on the positioning of the flexible duct core, the longevity of the flexible duct joints could not be based on the $10 \%$ of unsealed leakage criteria. Nevertheless, the leakage of the sealed specimens prior to testing, could be considered as a basis for a failure criteria. Visual inspection was also documented throughout the tests durations. The flexible duct core-to-collar joints were inspected monthly, while the sheet metal collar-to-plenum joints were inspected weekly. The baking test specimens were visually inspected weekly, and the longevity was judged by the observed deterioration in terms of brittleness, cracking, flaking and blistering (the terminology used in the UL 181B-FX test procedure). The baking specimens were ranked in terms of these deterioration criteria. The deterioration in the flexible duct coreto-collar joints was also ranked following the same criteria. This study concluded that the duct tape performance in sealing joints depends on the joint's geometrical dimensions; it gets worse as the number of dimensions required to describe the joint increases (1-D to 3-D). 1-D joints are the easiest to seal with duct tape, and thus the least to experience failure. However, this type of joints is rarely seen in field installations. 2D joints, such as the flexible duct core-to-collar joints tested in this study, are less likely to fail than 3-D joints, as the shrinkage could have a positive effect in tightening the seal. 3-D joints, such as the collar-to-plenum joint, are the toughest to seal, and therefore failure most rapidly. This is essentially caused by the shrinkage of the duct tape backing that results in the peeling of its rubber-based adhesive off the sheet metal fixture. The baking test results showed that the failure in the duct tape joints could be attributed to the type of combination of the duct tape and the material it is applied to.

\section{Introduction}

Air leakage in ducts has been identified as a major source of energy loss in residential buildings. Thirty to forty percent of air flow leaks in and out of ducting systems in residential buildings, and most of the duct leakage occurs at the connections to registers, plenums or branches in the air distribution system (Walker and Sherman 2000). This study is a continuation of previous studies conducted at LBNL (Walker et al. 1998a and 1998b, Walker and Sherman 2000, and Sherman et al. 2000), whose objectives are to develop new test methods for duct sealant longevity, evaluate different sealant types (e.g., tape, mastic, aerosol), facilitate the development of consensus standards (e.g., ASTM), and technology transfer. 
Joints in air-distribution systems can be characterized in terms of their geometrical space dimensions (1-D, 2-D, and 3-D). 1-D joints represent a joint between two flat surfaces, e.g., the longitudinal seam on sheet metal ducts. 2-D joints are usually perpendicular to the air flow where duct sections are connected, e.g., a flexible duct section to a sheet metal collar or between two sheet metal duct sections. 3-D joints are found at the connection of a collar to a flat plenum surface.

Underwriters Laboratory (UL) have developed safety standards for closure systems for use with rigid air ducts and air connectors, and flexible air duct and air connectors; UL 181A and UL 181B, respectively (UL 1993 and 1995). The current UL 181B-FX standard deals with field assembled flexible duct systems. UL 181B-FX is of a special importance to residential buildings since residential duct systems in the U.S. are normally field assembled. The standard covers pressure sensitive tape and mastic. Note that the UL 181B-FX standard only applies to tapes that have a mechanical clamp at the inner core of flexible duct to collar connection (but no clamp is required for the outer moisture barrier). However, none of the UL tests require the clamp to be in place, nor are the clamps tested. Six tests are prescribed for pressure sensitive tape: tensile strength, peel adhesion at $180^{\circ}$ angle, shear adhesion, surface burning, mold growth and humidity, and temperature tests. However, the standard has very limited tests of the longevity or durability of duct sealants. For example, the "sheer adhesion test" requires duct tape to sustain specified load without evidence of separation or slippage in excess of 1/8 in (3.2 $\mathrm{mm}$ ) for 24 hours only. While the UL tests address some important aspects of sealant performance, they do not adequately address longevity issues.

The Air Diffusion Council (ADC 1996) has standards providing recommendations for the installation of ducting systems, and requires the use of two wraps of duct tape over flexible duct core-to-collar joints. ADC does not provide recommendations for the collar-to-plenum joints.

Previous duct sealing tests conducted at LBNL covered two types of joints, core-tocollar, and collar-to-plenum, using sheet metal ducts and fittings. For the core-to-collar joints, the tape joined two concentric materials, thus exhibiting a 2-dimensional joint. However, the collar-to-plenum joints are typical when a metal collar attaches to a duct branch, splitter box, or a supply or return plenum. The collar-to-plenum joint was the most difficult to seal with duct tape because the leaks to be covered are not in a flat plane and the tape must be folded in order to conform to the joint. The round collar is mated through a circular hole to a flat piece of metal, with a set of flexible tabs that mechanically hold the collar in place with the use of sheet metal screws. The gaps between the tabs leave gaps of $1 / 8$ " to $1 / 4$ " ( 3 to $6 \mathrm{~mm}$ ).

Previous work at LBNL has progressed in several phases, with the exact experimental details changing as the test procedures were refined:

The first longevity testing was for evaluating the durability of the aerosol sealant technique developed at LBNL. This test alternately blew hot or room temperature air through sample joints with a 20 minute cycle time. 
The second phase of testing was initiated to examine a wide range of sealants and to make the testing more thorough by alternately blowing hot $\left(140^{\circ} \mathrm{F}\left(60^{\circ} \mathrm{C}\right)\right)$ or cold $\left(32^{\circ} \mathrm{F}\right.$ $\left.\left(0^{\circ} \mathrm{C}\right)\right)$ air through test sections, with pressures across the sealed leaks of about 0.8 inches of water $(200 \mathrm{~Pa})$. The addition of cooling allowed the tests to examine the effects of condensation and frost formation on longevity. The new apparatus used for the second phase of testing allowed simultaneous testing of eight samples. The second phase also included some simple baking tests were sample duct connections (the same as used in the cyclic temperature apparatus) were exposed to continuous high temperatures (between 140 and $176^{\circ} \mathrm{F}\left(60\right.$ and $\left.80^{\circ} \mathrm{C}\right)$ ) in an oven, with no temperature cycling and no pressure difference across the sealed leaks.

The third phase of testing was based on a new apparatus that could simultaneously have samples either continually cooled $\left(32^{\circ} \mathrm{F}\right.$ to $41^{\circ} \mathrm{F}\left(0^{\circ} \mathrm{C}\right.$ to $\left.\left.5^{\circ} \mathrm{C}\right)\right)$, continually heated $\left(150^{\circ} \mathrm{F}\right.$ to $180^{\circ} \mathrm{F}\left(66^{\circ} \mathrm{C}\right.$ to $\left.82^{\circ} \mathrm{C}\right)$, or cycled between the two extremes. The pressures across the sealed leaks varied over the range 0.4 to 0.8 inches of water (100 to $200 \mathrm{~Pa}$ ) depending on the testing mode. This larger apparatus could accommodate up to 30 samples in total and over 50 samples were tested. The testing during this phase confirmed previous results - the only sealants to fail are cloth backed rubber adhesive tapes, and heating only produces the most rapid failure.

The current study uses the same apparatus as the third phase - but has heating only and no cooling. This apparatus is described in more detail in the following section. Eighteen samples are simultaneously heated and pressurized, and the high temperature has been raised to $200^{\circ} \mathrm{F}\left(93^{\circ} \mathrm{C}\right)$ to more closely match that used in the UL $181 \mathrm{~B}-\mathrm{FX}$ temperature tests $\left(212^{\circ} \mathrm{F}\left(100^{\circ} \mathrm{C}\right)\right)$. The average pressure difference the specimens are exposed to in the apparatus is 0.34 inch water $(84 \mathrm{~Pa})$. In addition, we are replicating the UL 181B-FX temperature test by baking samples on substrates, i.e. not placed on duct connections.

These previous LBNL tests of duct tape longevity evaluated six types of sealants: (1) tape with vinyl or polyethylene backing with fiber reinforcement and rubber-based adhesive, (2) film tape with thin and clear polypropylene backing and acrylic adhesive, (3) foil tape with foil backing and acrylic adhesive, (4) butyl tape with foil backing and thick butyl adhesive, (5) mastic, an adhesive that dries to a semi-rigid solid, and (6) aerosol sealant, a sticky vinyl polymer blown inside the duct system.

In the current study only UL $181 \mathrm{~B}-\mathrm{FX}$ products were evaluated because many building codes now require that duct sealants be UL 181B-FX listed. Five different UL-listed duct tape products were used in the aging of flexible duct joints and the baking tests, generically called in this report as Tape 1, Tape 2, Tape 3, and Tape 4. For the aging of the sheet metal collar-to-plenum joints, two tapes were used; Tape 1, and an additional duct tape, Tape 5. Tapes 1 and 2 are conventional duct tapes. Tape 3 is a clear, Polypropylene backed, acrylic adhesive tape. Tape 4 is a foil-backed, butyl adhesive tape. Tape 5 is a prototype cloth-backed, butyl adhesive tape. 
For collar-to-plenum connections, the failure criteria is $10 \%$ of the leakage of the unsealed specimen prior to testing - with a correction for the small amount of remaining leakage after initial sealing (this is due to other small leaks on the sample as well as any remaining leakage past the duct sealant). The visual features of the specimen failure were also documented; drying and hardening of the adhesive, shrinking of the tape baking, delamination of the tape layers (backing/fiber/adhesive), and peeling of the tape off the medium it is applied to.

\section{Longevity Testing Facilities}

Figure 1 shows samples mounted on the aging test apparatus. Heated air is continuously circulated through the test apparatus to both heat and pressurize the leakage sites. The apparatus is divided into an upper and lower chamber that each contains nine (eight?) samples. The inside of the test samples are exposed to high pressure heated air and the outside (shown in Figure 1) is in an insulated chamber that also becomes heated during the experiments by conduction through the test samples. This means that there is little temperature gradient across the samples. The hot air temperature is controlled using electric resistance heaters mounted directly in the air stream. The surface temperatures of each sample, the air temperature and the pressure across the leaks are continuously monitored using a computer based data acquisition system. The actual leakage measurements are conducted periodically (typically on a monthly or weekly basis) by removing the samples from the test machine. They are then allowed to cool to room temperature before being placed in a separate testing device that pressurizes the samples to $25 \mathrm{~Pa}$ and measures the air flow rate required to maintaining this $25 \mathrm{~Pa}$ pressure difference. This $25 \mathrm{~Pa}$ air flow is the leakage of the sample that is then recorded and compared to initial $25 \mathrm{~Pa}$ air flow measurements of the connections before and after initial sealing.

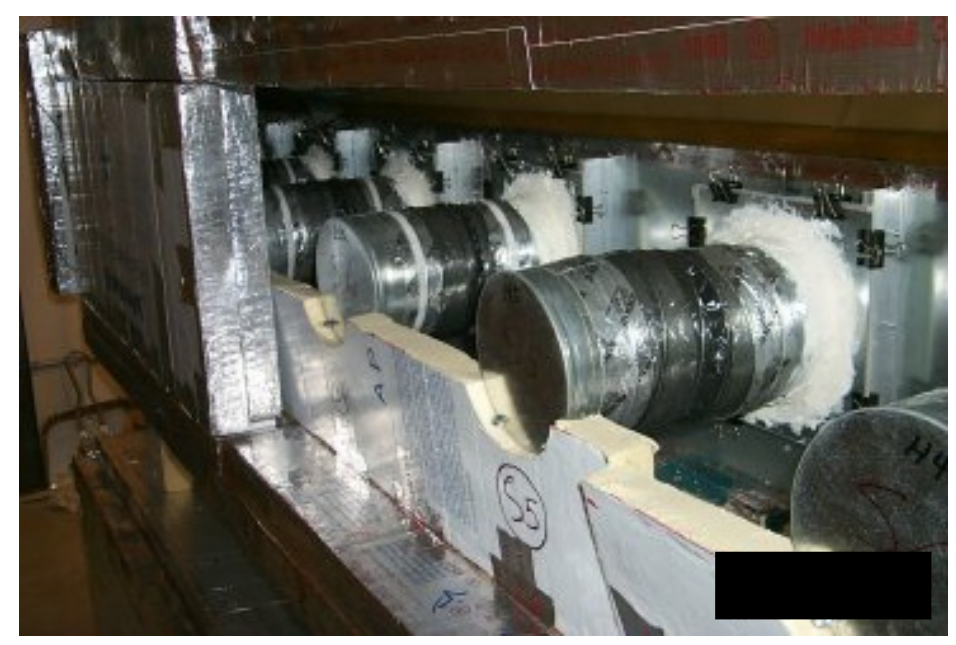

Figure 1. One chamber of the high temperature aging test apparatus.

Figure 2 shows a schematic of the hot air circulation path in the aging test apparatus. The upper and lower test chambers are connected by insulated ducting so that the same air flows through both chambers and only one heater is required. In the previous phase of 
testing, the lower chamber had cold air circulating through it. This apparatus conforms to proposed ASTM test requirements in order to develop an industry standard test method.

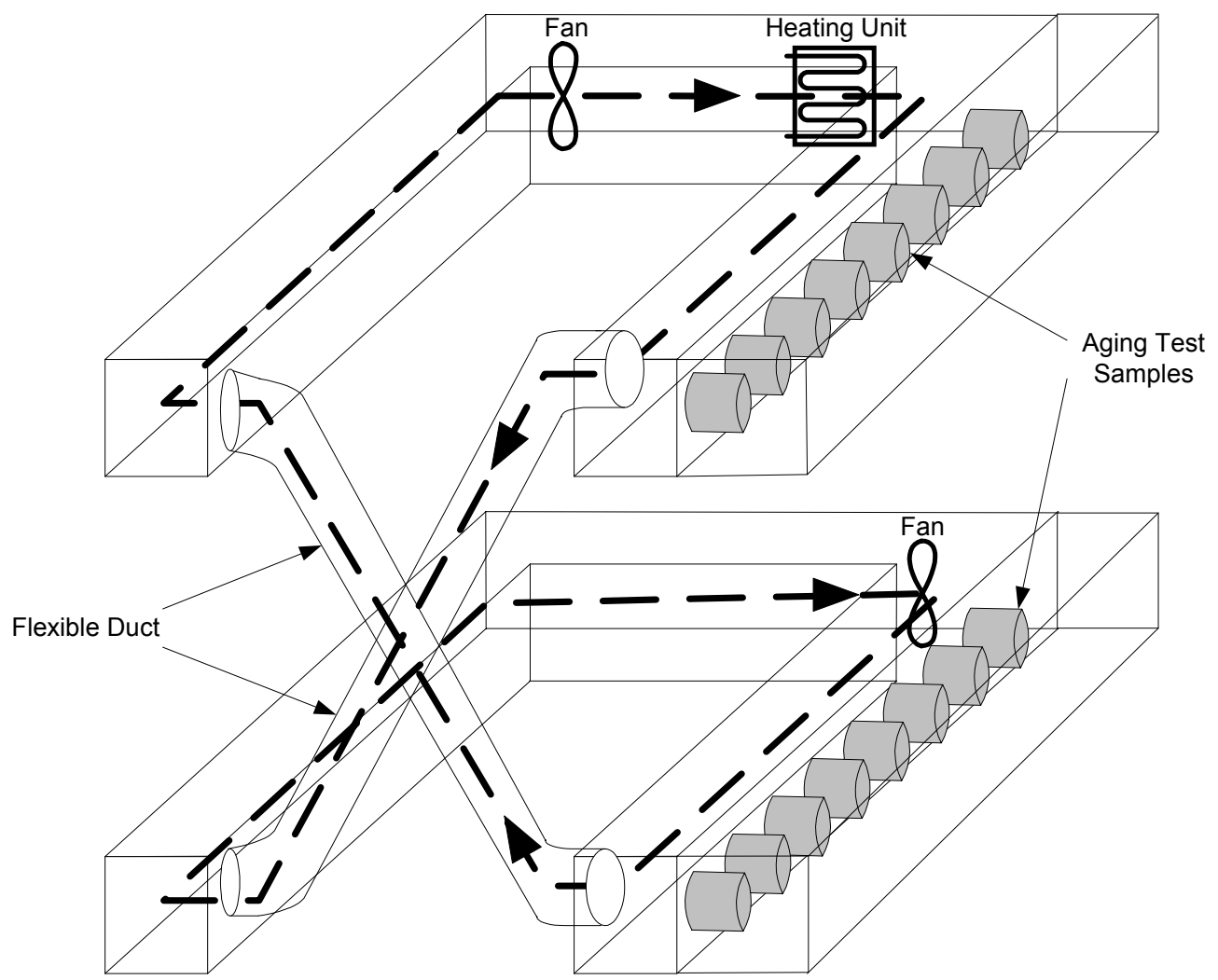

Figure 2. The hot air circulation in the modified aging test apparatus.

Figure 3 shows the baking test oven that provides constant circulating air temperature of $212^{\circ} \mathrm{F}\left(100^{\circ} \mathrm{C}\right)$ for the baking specimens following the UL $181 \mathrm{~B}$ "temperature test" protocol. All walls of the oven are made with 4" $(100 \mathrm{~mm})$ thick foil-faced foam sheathing. The bottom of the oven, sitting on the floor, is made thicker $(6$ " $(150 \mathrm{~mm}))$ for added insulation. The oven is $44 "(112 \mathrm{~cm})$ high, 72" $(183 \mathrm{~cm})$ wide, and $10 "(25 \mathrm{~cm})$ deep. It contains four racks made of two strips of aluminum that hold the testing specimens. Six temperature sensors equidistantly placed on both sides of the oven provide readings of the temperature profile inside the oven. Measured results show that the temperatures do not vary by more than $5^{\circ} \mathrm{F}\left(2.5^{\circ} \mathrm{C}\right)$ from the average temperature of $212 \pm 5^{\circ} \mathrm{F}\left(100 \pm 3^{\circ} \mathrm{C}\right)$. The oven has an electric heating unit controlled by a relay box to turn off at $214^{\circ} \mathrm{F}\left(101^{\circ} \mathrm{C}\right)$ and on at $210^{\circ} \mathrm{F}\left(99^{\circ} \mathrm{C}\right)$, and also protected by a safety snap thermostat rated at $250^{\circ} \mathrm{F}\left(121^{\circ} \mathrm{C}\right)$. The temperature values are recorded at a one-minute interval. The air circulation inside the oven is insured by a thermally-protected ballbearing 115 volts. 


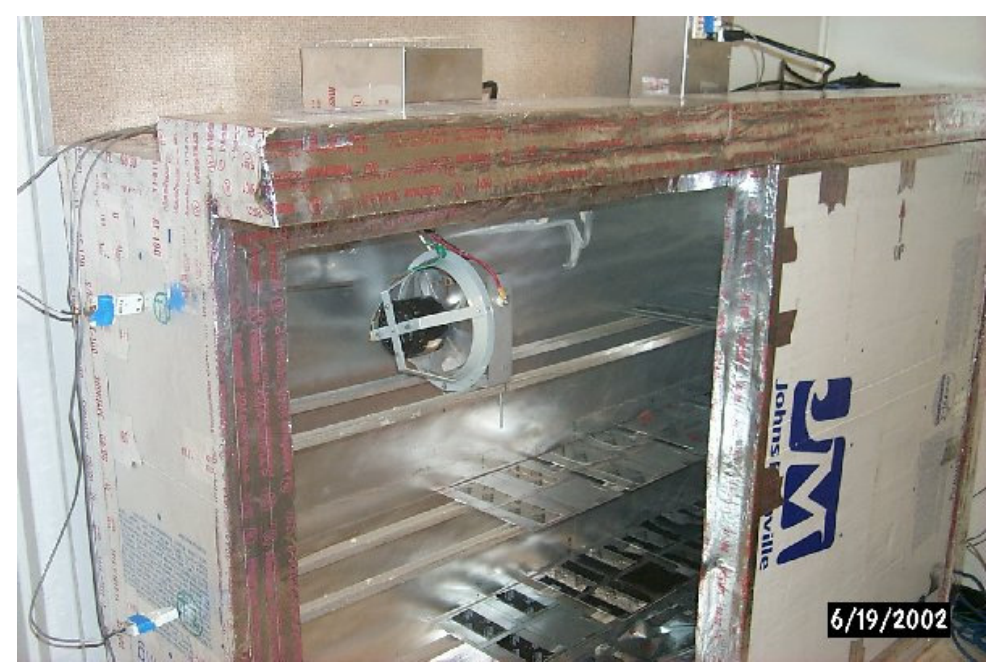

Figure 3. The high temperature baking apparatus.

\section{Temperature Effect on Leakage Measurements}

Because the aging test involves heating the specimens continuously at $200^{\circ} \mathrm{F}\left(93^{\circ} \mathrm{C}\right)$, it takes some time for the specimens to return to room temperature. Therefore the elapsed time between removal from the test chamber and measurement of leakage could have an effect on the results. To examine this effect, a specimen was tested six times at 15minute intervals, with the first measurement taken at its highest temperature $\left(200^{\circ} \mathrm{F}\right.$ $\left(93^{\circ} \mathrm{C}\right)$ ). The experiment took place in the laboratory where room temperature is $77^{\circ} \mathrm{F}$ $\left(25^{\circ} \mathrm{C}\right)$. Figure 4 shows the decay in the leakage flow as a function of cool-off time. The leakage flow at the highest temperature is $16 \%$ higher than the last value taken 1 hour and 15 minutes later. The difference in leakage is attributed to the "re-sealing" of the joint as it shrinks and hardens at lower temperatures. For consistent results the samples need to cool to room temperature before being leakage tested. However, for some of thest results discussed here we did not wait a uniform time, which resulted in additional uncertainty in measured sample leakage. 


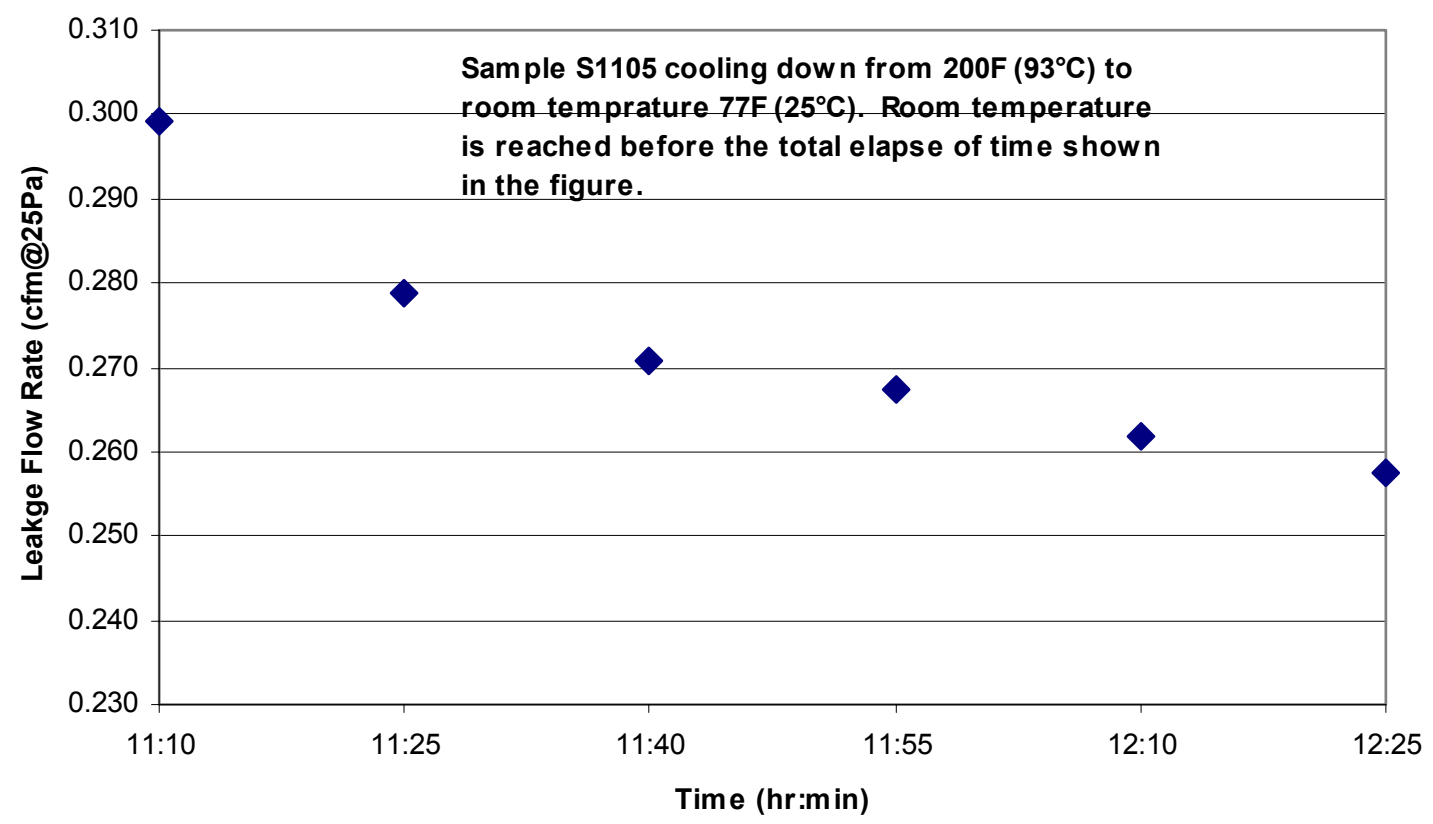

Figure 4. Decay in the measured leakage as the specimen cools down from 200F $\left(93^{\circ} \mathrm{C}\right)$ to room temperature.

\section{Aging Test Experimental Conditions}

The difference between the tests conducted in this study and previous tests, is in the type and construction of the specimens and the temperature of the tests. Previously, in Walker et al. (1998a and 1998b), Walker and Sherman (2000), and Sherman et al. (2000), the aging tests concentrated on the 4" $(100 \mathrm{~mm})$ collar-to-plenum joint. Because UL 181BFX products are the focus of this study, the test joint was changed to the flex duct to collar connection that the UL testing concentrates on. Specifically, a 6" $(150 \mathrm{~mm})$ diameter flexible duct core to sheet metal collar joint is used.

Flexible ducts consist of three layers: inner membrane called "core", a layer of insulation and an outer layer acting as a moisture barrier called a "jacket". The test samples were sealed with two layers (one continuous piece) of duct tape applied to the core of the duct with the insulation and outer moisture barrier removed. The taped joint is reinforced with a mechanical plastic clamp installed over the tape as required for UL 181 B-FX installations. Figure 5 shows a laboratory construction of the 6 " $(150 \mathrm{~mm})$ flexible coreto-collar joint aging test specimens, which contains two core-to-collar joints (the joint being tested) and one collar-to-plenum joint (not tested and sealed with mastic). The white irregular ring of material at the back (left) is mastic that has been applied over the collar-to-plenum joint. The end of the duct is capped with a metal cap that is sealed before testing. Figure 6 shows a schematic of the flexible duct core-to-collar joint as it is fits on the aging test apparatus. Figure 6 shows how the whole specimen is enclosed in insulation that forms a test chamber. 


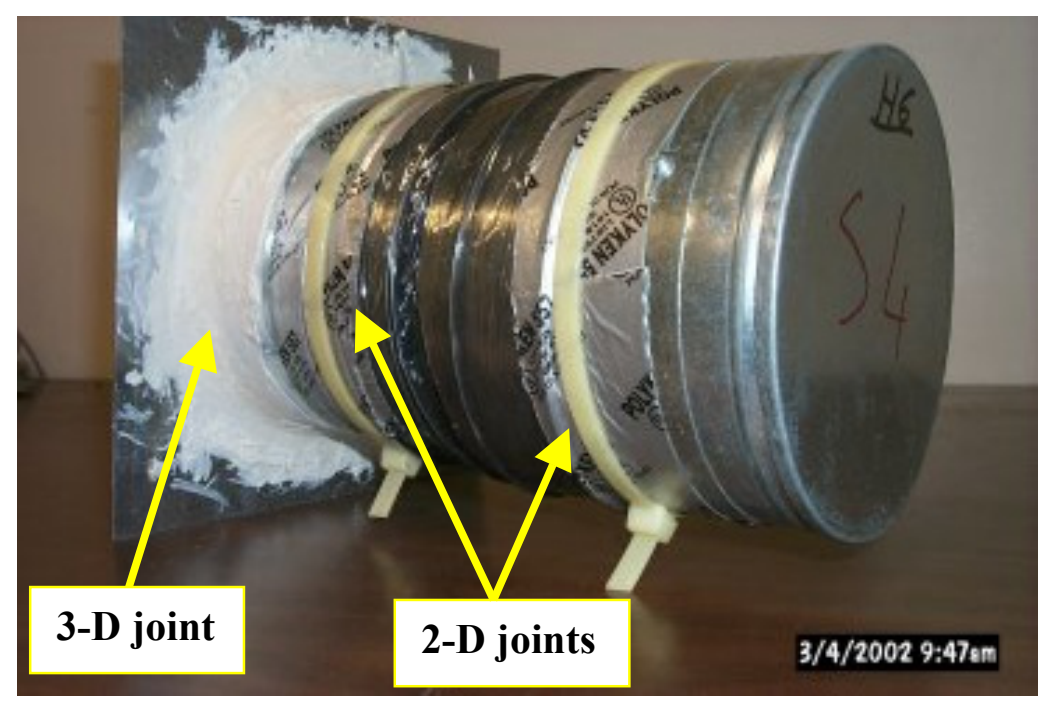

Figure 5. Example of test sample showing the two taped connections and the mechanical clamps.

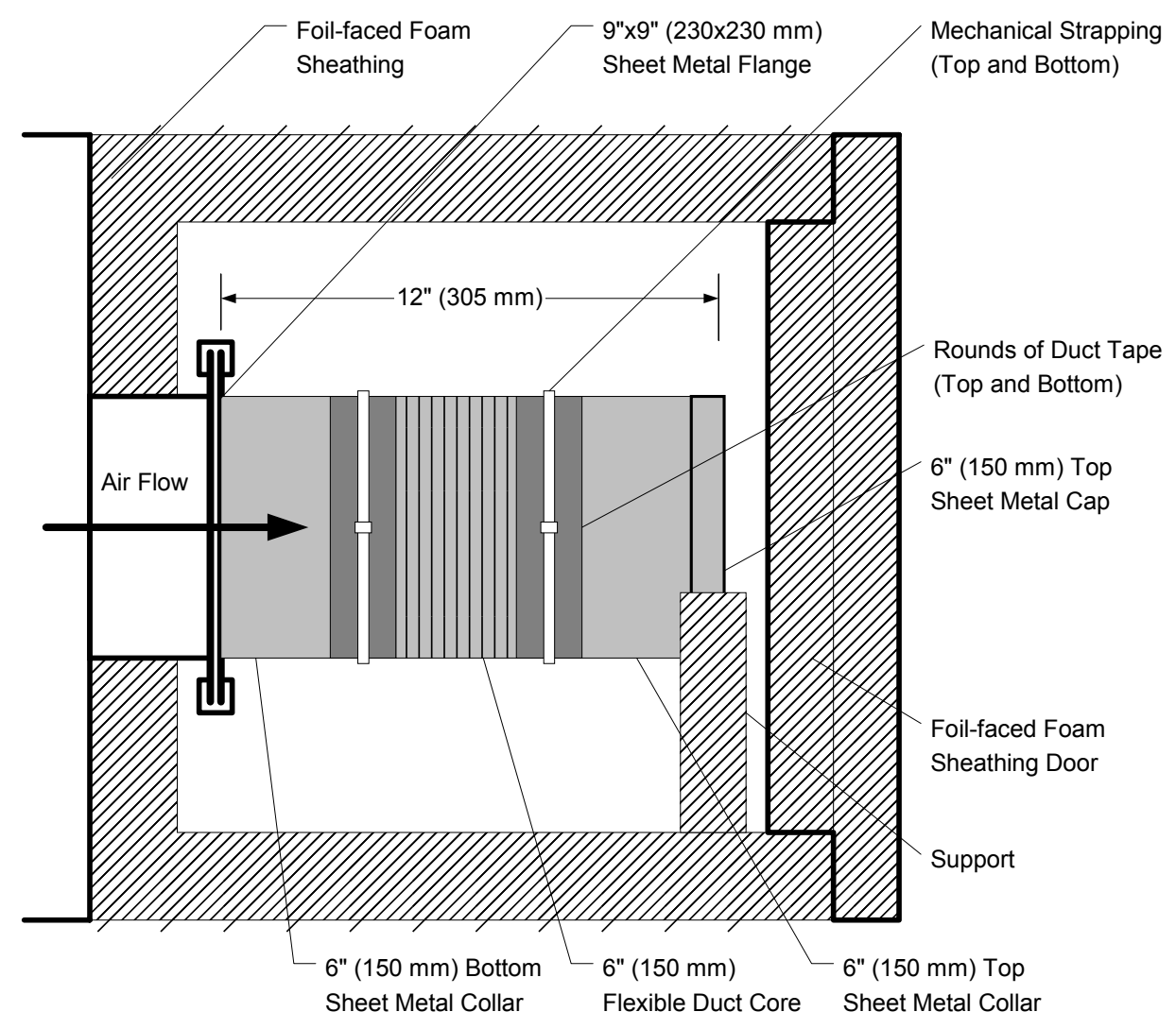

Figure 6. A side-view schematic of a flexible duct core to sheet metal collar joint specimen positioned on the aging test apparatus. 
We also tested samples without mechanical clamping because this configuration is commonly found in field installations. Also, clamps are only required on the inner core and not on the outer moisture barrier by UL 181 B-FX. The taping technique was changed for some samples to include discontinuous wrapping and only a single layer of tape instead of two. Table 1 shows the 18 combinations tested in this study.

In addition to the aging tests of the flexible duct core-to-collar joints we also repeated the collar-to-plenum 4" $(100 \mathrm{~mm})$ joints aging tests that were conducted in previous studies, in order to test a new duct tape product that can sustain $200^{\circ} \mathrm{F}\left(93^{\circ} \mathrm{C}\right)$ temperature (Tape $5)$.

Table 1. Various Combinations of Core-to-Collar Joint Construction Used in the Aging Tests of this Study.

\begin{tabular}{|c|c|c|c|c|c|}
\hline Tape \# & Type & $\begin{array}{c}\text { Specimen \# } \\
\text { (7000 Series) }\end{array}$ & Clamping & $\begin{array}{c}\text { \# of Tape } \\
\text { Wraps }\end{array}$ & $\begin{array}{c}\text { Continuous } \\
\text { Wrapping }\end{array}$ \\
\hline \multirow[t]{8}{*}{ Tape 1} & \multirow[t]{8}{*}{ Duct Tape } & S7001 & $*$ & 2 & * \\
\hline & & S7002 & $*$ & 2 & \\
\hline & & S7003 & $*$ & 1 & $*$ \\
\hline & & S7004 & $*$ & 1 & \\
\hline & & S7005 & & 2 & $*$ \\
\hline & & S7006 & & 2 & \\
\hline & & S7007 & & 1 & $*$ \\
\hline & & S7008 & & 1 & \\
\hline \multirow[t]{4}{*}{ Tape 2} & \multirow[t]{4}{*}{ Duct Tape } & S7009 & $*$ & 2 & $*$ \\
\hline & & S7010 & $*$ & 2 & \\
\hline & & S7011 & & 2 & $*$ \\
\hline & & S7012 & & 1 & \\
\hline \multirow[t]{3}{*}{ Tape 3} & \multirow[t]{3}{*}{ Film Tape } & S7013 & $*$ & 2 & $*$ \\
\hline & & S7014 & $*$ & 1 & $*$ \\
\hline & & S7015 & & 2 & \\
\hline \multirow[t]{3}{*}{ Tape 4} & \multirow{3}{*}{$\begin{array}{c}\text { Foil-Butyl } \\
\text { Tape }\end{array}$} & S7016 & $*$ & 2 & $*$ \\
\hline & & S7017 & $*$ & 1 & \\
\hline & & S7018 & & 1 & $*$ \\
\hline
\end{tabular}

\section{Baking Test Experiment}

For each duct tape (Tape 1, Tape 2, Tape 3, and Tape 4), twelve specimens were made by applying a strip of tape to three 4 by 4 inch $(100$ by $100 \mathrm{~mm})$ samples of each of the following materials: aluminum foil, polyethylene, polyethylene terephthalate (PET), and sheet metal (steel). Another 4 by 4 inch $(100$ by $100 \mathrm{~mm})$ control sample of each of the substrate materials is included in the specimen without applying the tape to it. The control sample serves as a means to quantify the deterioration attributed to the substrate in isolation from the duct tape. A specimen set in the baking test, therefore consists of three similar samples and one control sample, all carried by a sheet metal tray in the oven (Figure 7). Since the substrates used in this test are very thin and light weight, they are 
attached from two sides to the sheet metal tray so that the fan can not blow them away from their locations.

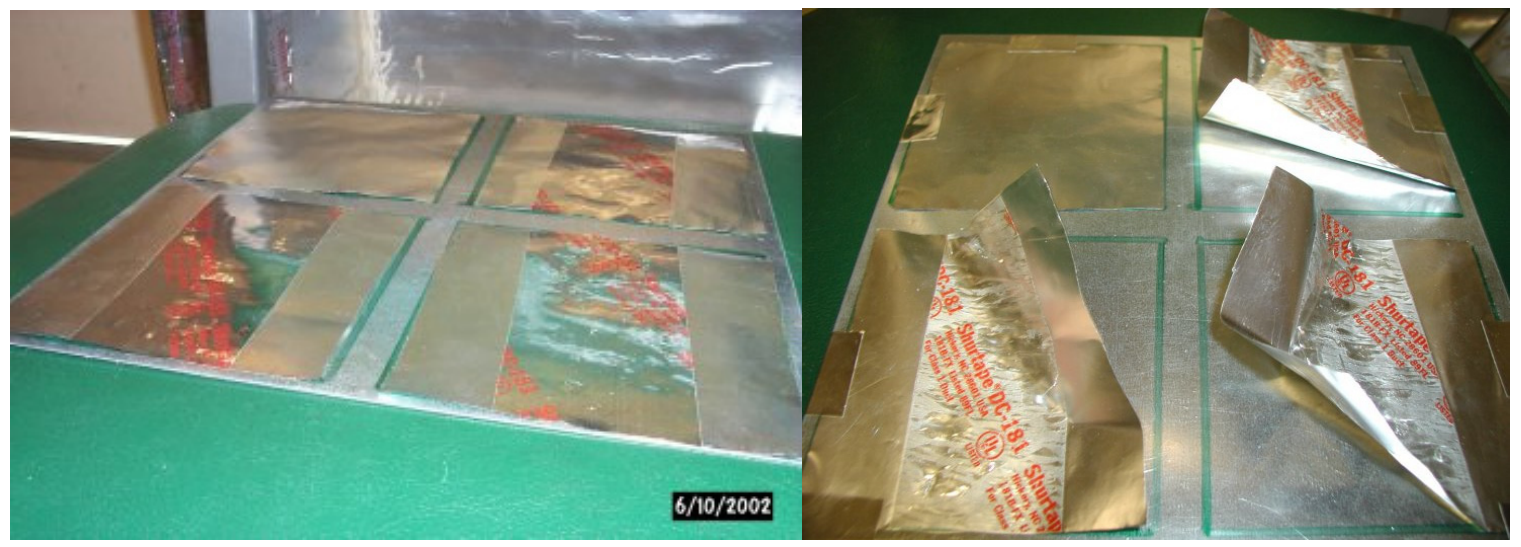

Figure 7. A baking specimen following the UL 181B temperature test protocol consisting of three samples of tape (Tape 3) and one control sample of the substrate (Aluminum Foil) before testing and after four weeks of testing.

In addition to the specimens following the UL 181B temperature test protocol, we included "hanging specimens" (Figure 8) of all four tapes in the oven to examine their deterioration in isolation from the substrate they are applied to.

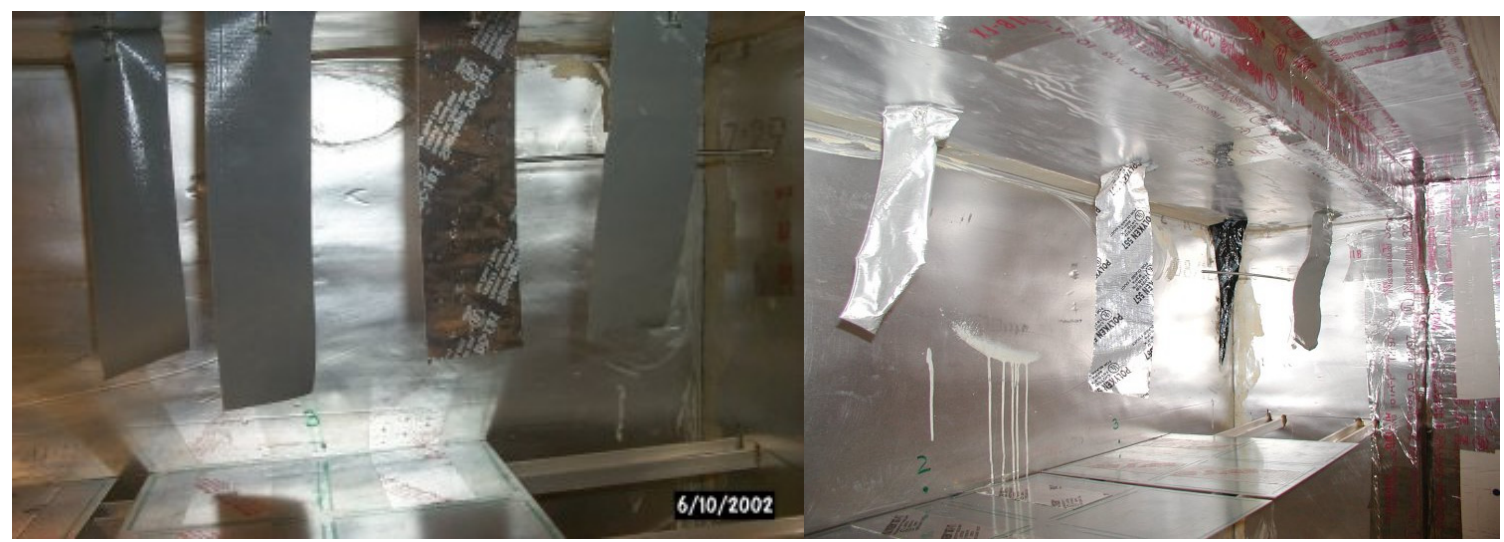

Figure 8. Hanging specimens of Tapes 1 to 4 in the high temperature baking apparatus before testing and after three weeks of testing.

In this type of tests, visual inspection is an indicator of the tape failure. The baking test specimens are visually inspected weekly, and the longevity is judged by the seen deterioration in terms of hardening, brittleness, peeling, shrinkage, wrinkling, delamination, flaking, cracking, bubbling, oozing and discoloration.

\section{Results}

A standard pressure of $25 \mathrm{~Pa}$ was chosen for leakage measurements of individual sealants because this is a typical pressure that would exist in the branches of a residential duct 
system (Walker and Sherman 2000). The flexible core-to-collar joint specimens underwent an initial six months period (starting in February 2002) of aging with visual inspection and leakage measurements once a month. The sheet metal collar-to-plenum joints tend to fail much faster core-to-collar joints and they were therefore tested once a week and replaced as they failed. The samples in the baking test underwent the 60 days period of testing as required by the UL 181B standard "temperature test", with visual inspection once a week.

Flexible core-to-collar joints aging test. Measuring the leakage in a flexible duct coreto-collar specimen prior to applying the duct tape (sealing), cannot be taken as a baseline leakage in the analysis. The reason is that the flexible duct does not fit firmly on the sheet metal fitting and thus the unsealed joint is relatively much leakier than one made with two sheet metal sections. In addition, being flexible, the way the core is placed around the sheet metal collar can make a considerable difference in the amount of leakage. An unsealed specimen was tested and the leakage changed by up to $30 \%$ when the test was repeated by only changing the positioning of the flexible core around the sheet metal collar, and up to $40 \%$ among different flexible duct configurations (stretched, bent, compressed). Therefore we considered the base case to be the initial sealing prior to testing; the failure criteria could then be characterized by the changes in the leakage, as well as visual inspection. Table 2 shows the detailed repeatability and variability results of the unsealed leakage of a flexible duct core-to-sheet metal collar specimen.

Table 2. Repeatability and Variability of Unsealed Leakage of a Flexible Duct Coreto-Sheet Metal Collar Specimen for the Aging Test.

\begin{tabular}{|c|c|c|c|c|}
\hline \multirow{3}{*}{$\begin{array}{c}\text { Data } \\
\text { Set }\end{array}$} & $\begin{array}{c}\text { Compressibility } \\
\text { and Bending } \\
\text { of Flexible Duct }\end{array}$ & $\begin{array}{c}\text { Leakage } \\
\text { Flow } \\
\text { (cfm } \mathbf{0 2 5 P a )}\end{array}$ & $\begin{array}{c}\text { Repeatability } \\
\text { Error } \\
\text { (across data sets) } \\
(\mathbf{\%})\end{array}$ & $\begin{array}{c}\text { Variation } \\
\text { Error } \\
\text { (within each data set) } \\
\mathbf{( \% )}\end{array}$ \\
\hline \multirow{3}{*}{1} & Straight - Fully Stretched & 2.6 & - & - \\
\cline { 2 - 5 } & Bent 45 & 1.5 & - & -41.2 \\
\cline { 2 - 5 } & Maximum Compression & 2.3 & - & -11.8 \\
\cline { 2 - 5 } & Average Compression & 2.9 & - & 14.3 \\
\hline \multirow{2}{*}{2} & Straight - Fully Stretched & 2.0 & -22.3 & - \\
\cline { 2 - 5 } & Bent 45 & 1.7 & 14.7 & -13.1 \\
\cline { 2 - 5 } & Maximum Compression & 1.9 & -17.1 & -5.9 \\
\cline { 2 - 5 } & Average Compression & 2.0 & -32.2 & -0.2 \\
\hline
\end{tabular}

${ }^{1}$ Two data sets were generated by changing the positioning of the flexible duct core on the top and bottom sheet metal collar forming the joints; the flexible core does not fit tightly on the collars.

In order to systematically record the visual deterioration of the samples, monthly pictures of all 18 specimens were taken. Typical minor deteriorations were observed as discoloration, wrinkling, and oozing, and major deteriorations were shrinking, peeling, delamination, and cracking. Figure 9 shows the deterioration of one of the specimens with clamping, and 2 continuous wraps of duct tape.

After the first month of aging at $200 \pm^{\circ} 5 \mathrm{~F}\left(93 \pm 3^{\circ} \mathrm{C}\right)$, all 18 specimens showed the following deterioration, increasing with time: 
- shrinkage and delamination among the unclamped specimens (Figure 10)

- oozing of the adhesive layer in the foil-butyl tape (Tape 4) specimens (Figure 11)

- little shrinkage and delamination in the strapped specimens

- discoloration of the plastic strapping in the clamped specimens

The discoloration of the plastic strapping was an indication of its deterioration which basically lead to a total failure afterward in one case (specimen S7014) after four months of aging The plastic clamp cracked open due to the increased brittleness of the plastic (Figure 12).

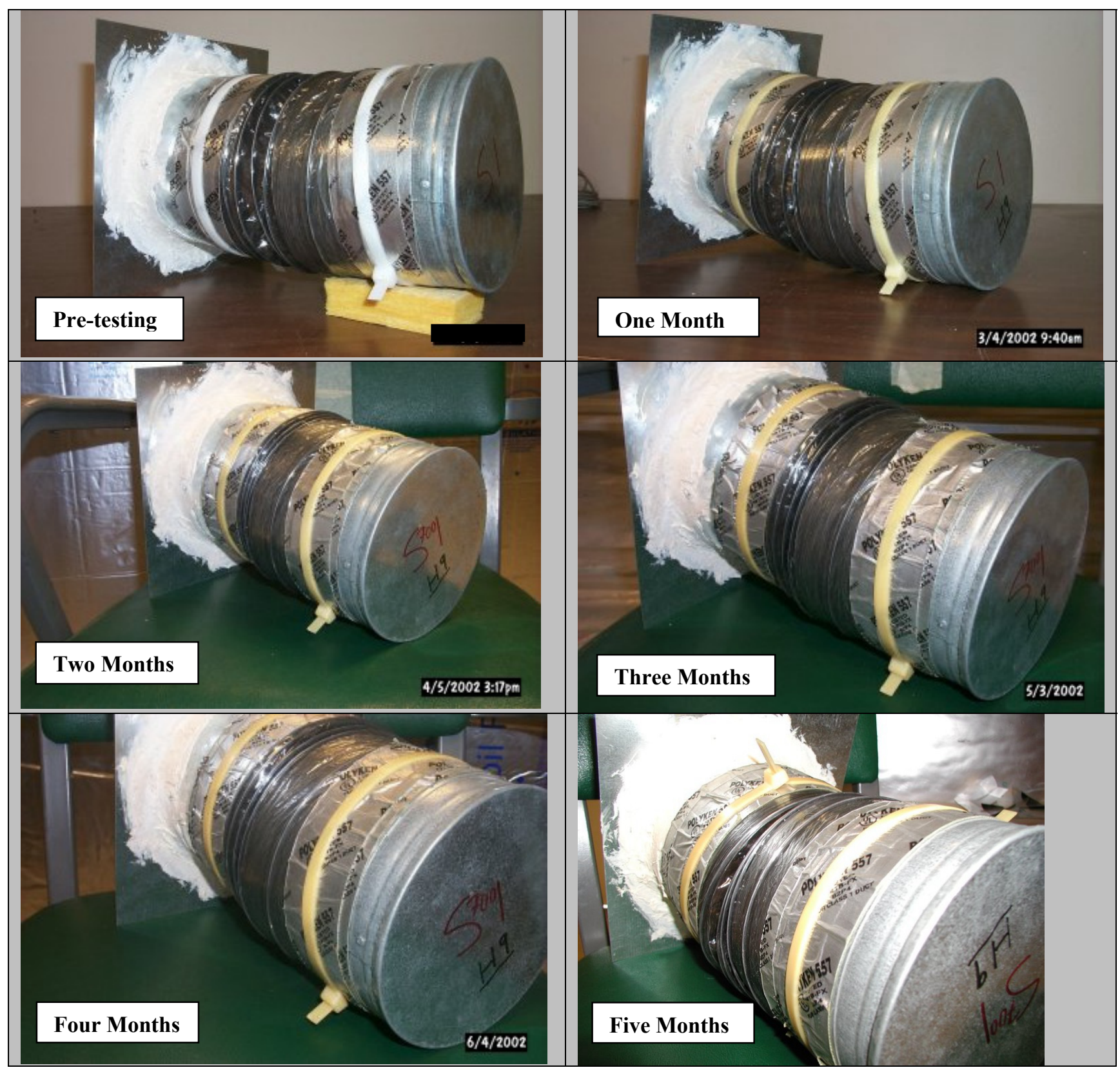




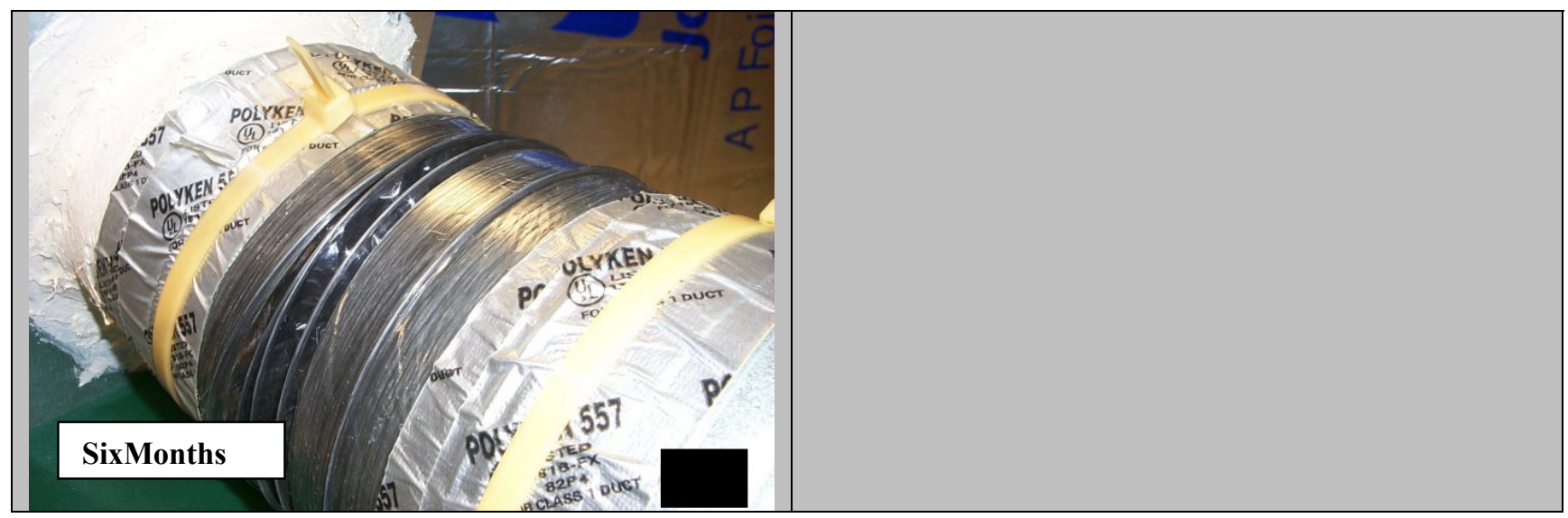

Figure 9. Deterioration of flexible duct core-to-sheet metal collar joint during the six months of the aging test at $200 \mathrm{~F}\left(93^{\circ} \mathrm{C}\right)$ temperature.

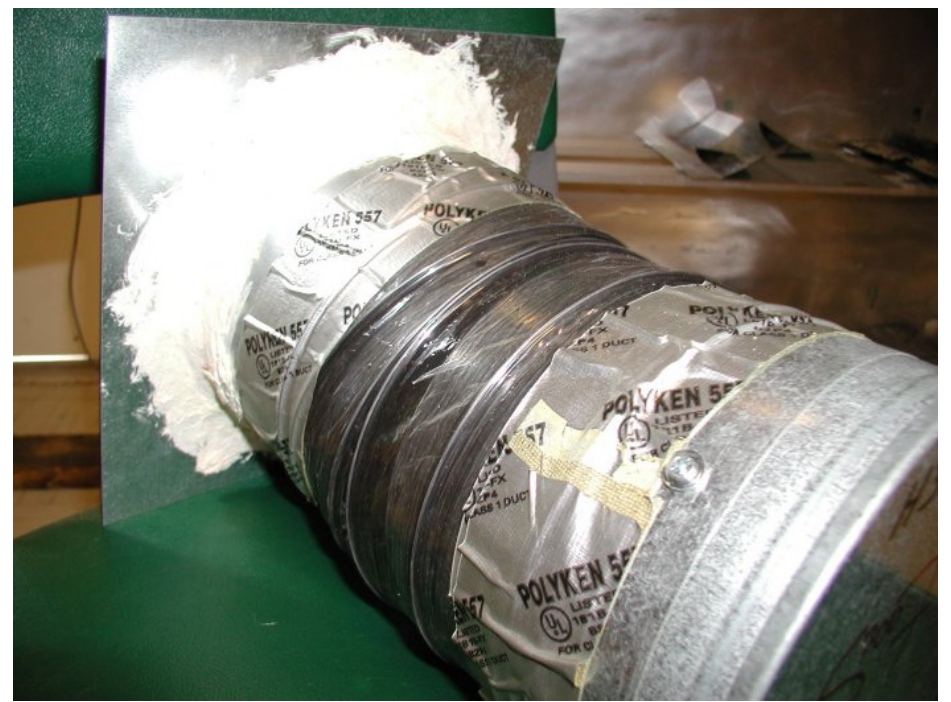

Figure 10. Shrinkage and delamination among the unclamped specimens (showing here result of 5 months of aging) 


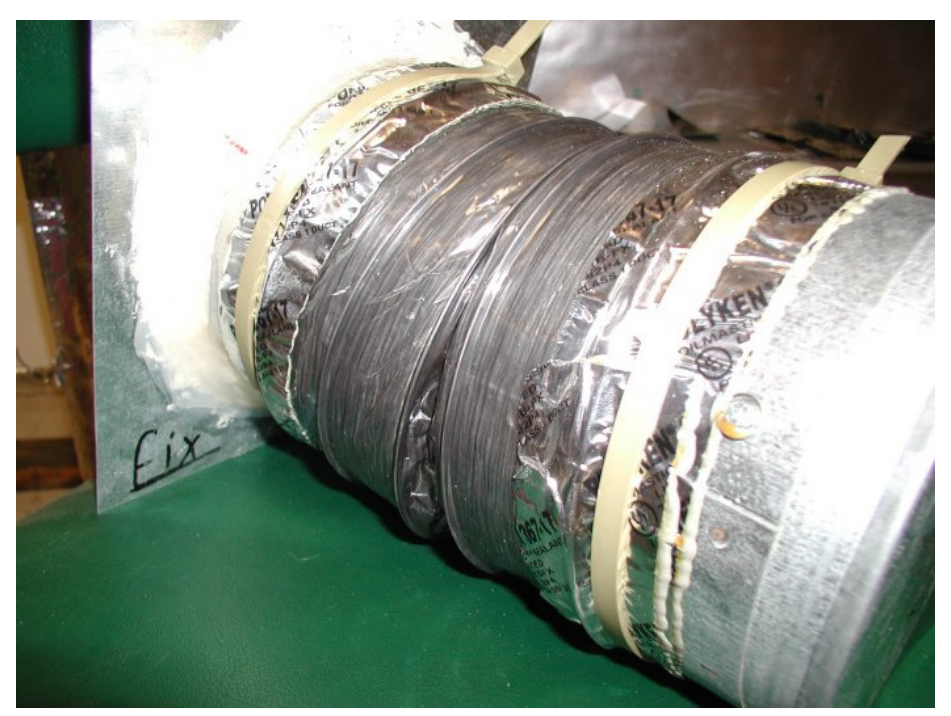

Figure 11. Oozing of the adhesive layer in the foil-butyl tape (Tape 4) specimens (showing result of 5 months of aging).

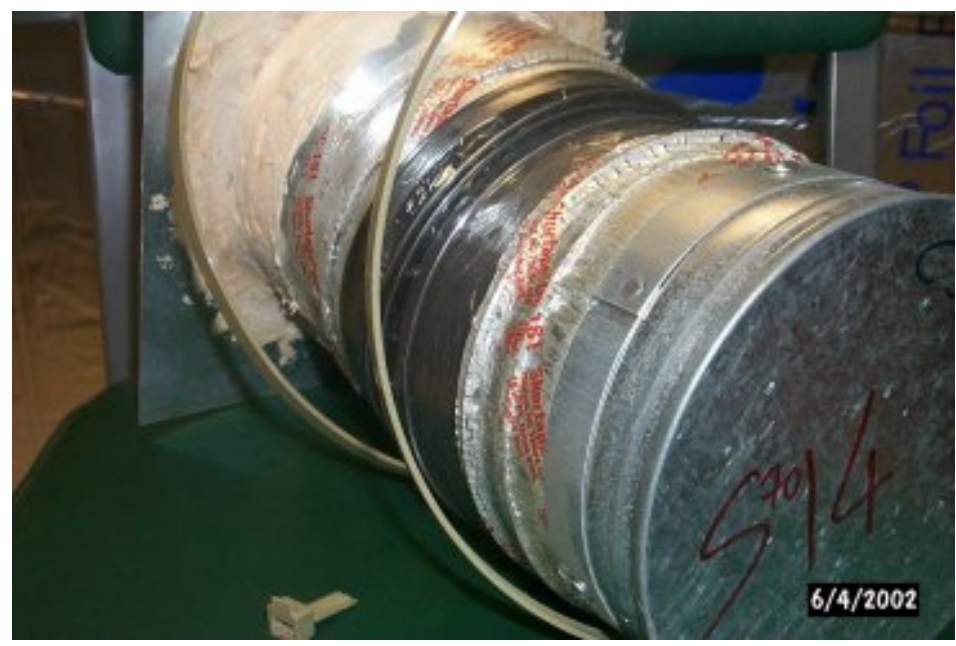

Figure 12. The failed plastic strapping on one of the flexible core to sheet metal collar specimens after four months of aging.

The results are separated in two figures (13 a and b) for clarity. These results show all but one of the samples having an increase in leakage after the first month of testing. After this first month there are no clear universal trends with both increases and decreases in leakage of different magnitudes for different samples. The cases of decreases in leakage illustrate some of the limitations of our test procedure in terms of the resolution of the leakage tests and other issues, such as the changes due to temperature of the test sample during leakage testing (discussed earlier). For example, for the most recent tests, we waited until the samples were cool before testing, which leads to lower measured leakage. In the earlier measurements we did not consider waiting for temperature 
stabilization and tested the samples at some intermediate temperature, thus leading to higher measured leakage. The magnitude of the changes in leakage with time and therefore sample temperature shown in Figure 4 indicate that the negative leakage shown in Figures 13a and $\mathrm{b}$ is of a similar magnitude to this effect. In addition, a general observation of the core-to-collar joints undergoing an aging test is that the shrinkage of the duct tape can have a positive effect as it tightens up around the joint, unlike the case of a collar-to-plenum joint where the shrinkage of the duct tape makes it peel off and pull away from the surface it is applied to, thus exposing the leaks.

After the initial six-month period of aging, the flexible duct core-to-collar specimens showed increases in leakage, but no catastrophic failures. However, the visual inspection of the specimen showed the effects of the temperature and pressure during the aging test. The observations as a result of the visual inspection after the six-month period of testing are summarized in Table 3. Table 3 assigns points ( 0 to 2$)$ to each of the ten features of the degradation; " 0 " denoting either "no sign of deterioration" in that category (feature), " 1 " denoting a "moderate deterioration", and " 2 " denoting an "excessive deterioration". These points are somewhat subjective, but they do serve to give a relative rating for each tape. The table also includes the total number of points given to each specimen. It can be clearly seen that specimens S7013, S7014, and S7015 (all Tape 3, polypropylene tape) showed the most deterioration, while specimen S7009 (Tape 2, duct tape with clamping, two continuous wraps), and specimens S7017 (Tape 4, foil-butyl tape, with clamping, and one discontinuous wrap), and S7018 (Tape 4, foil-butyl tape, without clamping, and one continuous wrap) showed the least deterioration. When the specimens were clamped (S7001, S7002, S7003, and S7004), only the cloth mesh (reinforcement) layer of the tape experienced the shrinkage, whereas in the clamped specimens (S7005, S7006, S7007, and S7008) all layers of the tape experienced the shrinkage.

A general observation of the core-to-collar joints undergoing an aging test is that the shrinkage of the duct tape can have a positive effect as it tightens up around the joint, unlike the case of a collar-to-plenum joint where the shrinkage of the duct tape makes it peel off and pull away from the surface it is applied to, thus exposing the leaks. 

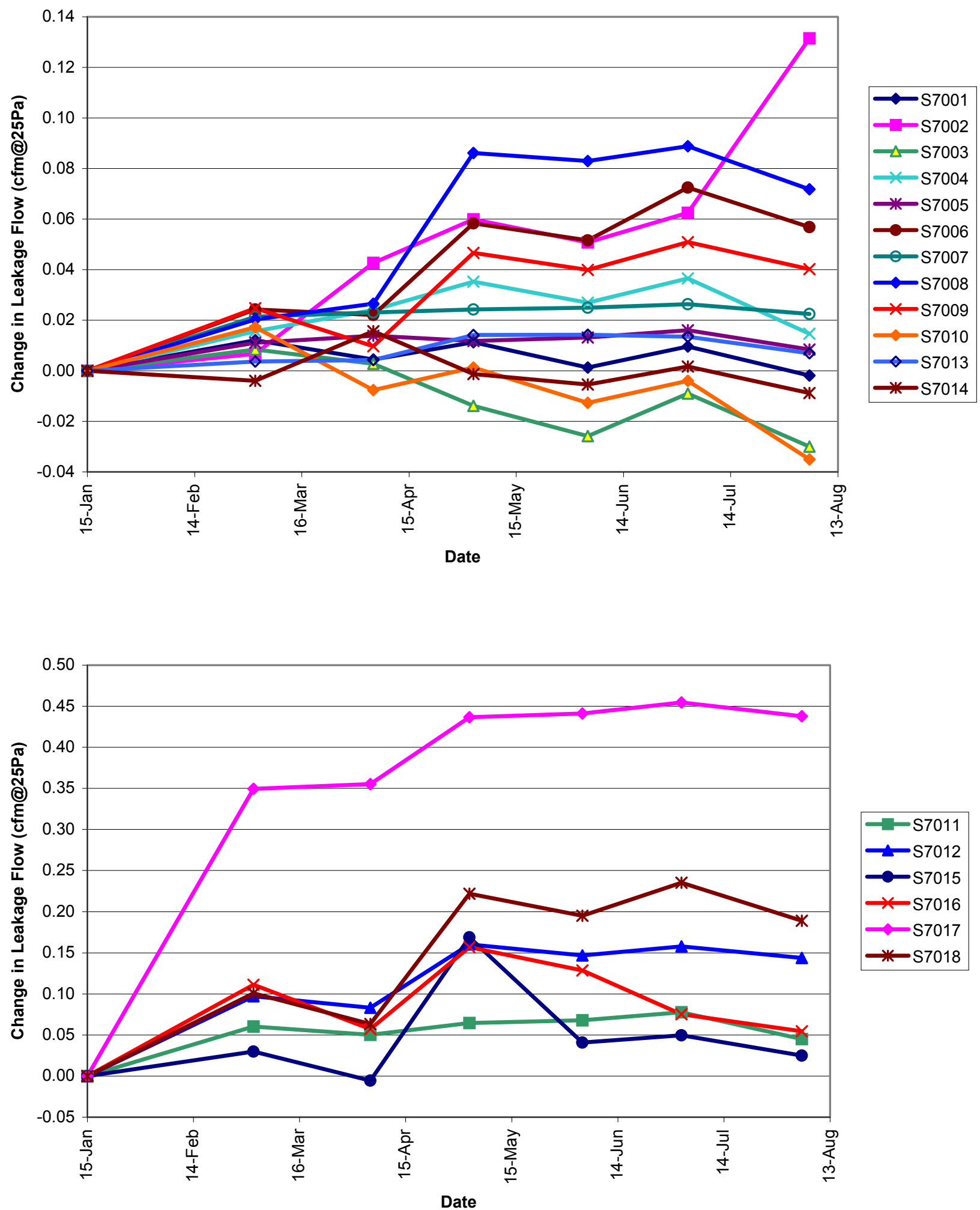

Figure 13 (a and b). The measured change in leakage flow of the flexible core to sheet metal collar joint specimens during the six-month period of the aging test. 


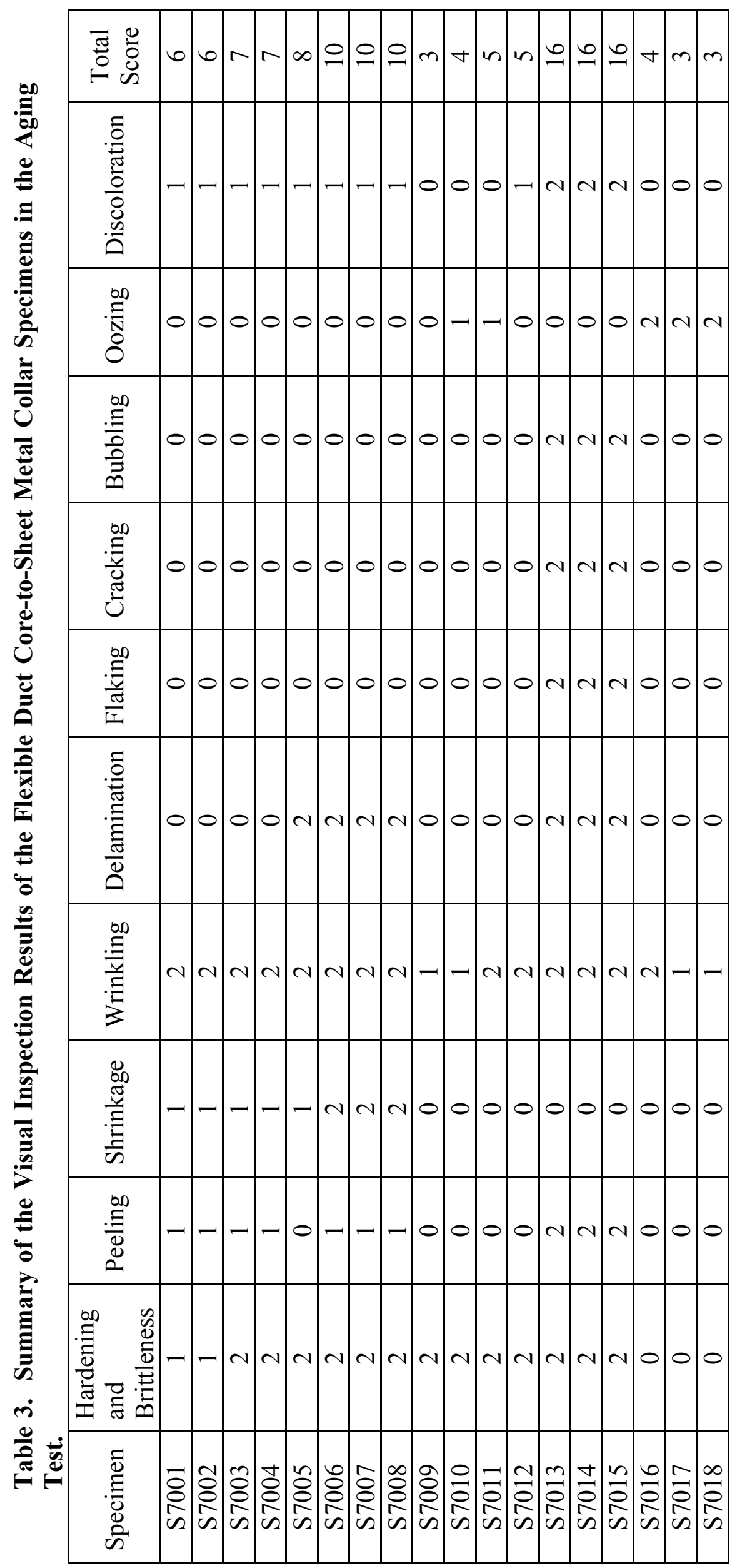


Collar-to-plenum joints aging test. In addition to the aging tests of the flexible duct, core-to-collar joints, we also repeated the tests of the collar-to-plenum joints aging tests that were conducted in previous studies. These tests were performed for a new duct tape product that has been developed to have improved high temperature performance (Tape 5) as well a sample of Tape 1 . The tape new failed in 9 days (using the $>10 \%$ of unsealed leakage criteria), showing shrinkage and pulling away from the sheet metal plenum. Figures 14 and 15 show the results of these tests. Because they were mounted in a different location on the test apparatus, these collar-to-plenum were exposed to different temperatures than the core to collar samples. These samples were placed between the left and right chambers (shown in Figure 2) where in previous phases of longevity testing the samples experienced cycling temperatures. Table 4 shows the temperatures the specimens were exposed to during the test, and the corresponding elapsed time before failure. Specimen S1102 failed after 2.5 months, and was replaced with specimen S1105. Specimen S1105 appeared to leak at a faster rate at the beginning, then leveled off, then showed a catastrophic (sudden) failure, contrary to the gradual failure of S1002). It took specimen S1 105 only one month and three weeks to fail.

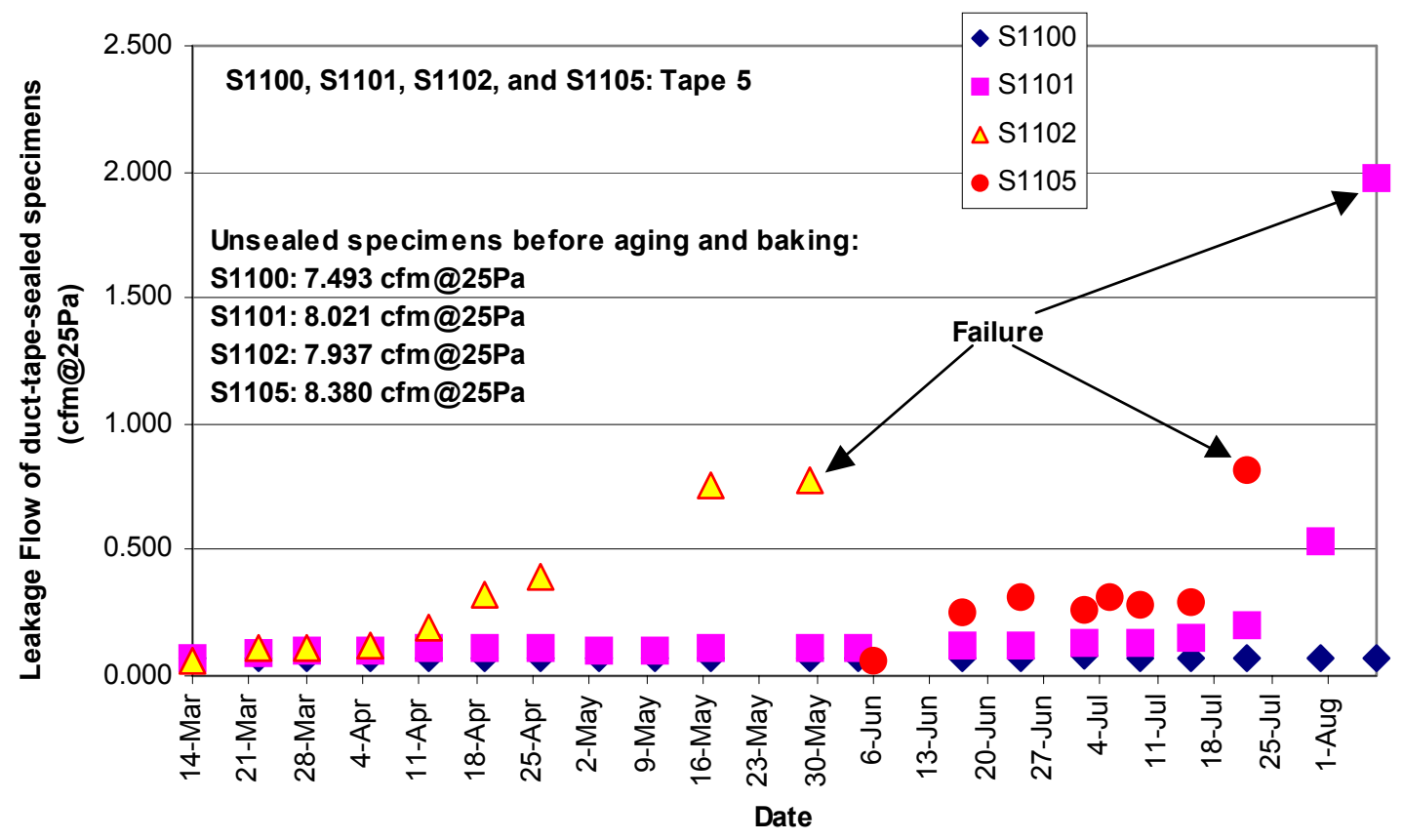

Figure 14. The measured leakage of the collar-to-plenum joint Tape-5 specimens. 


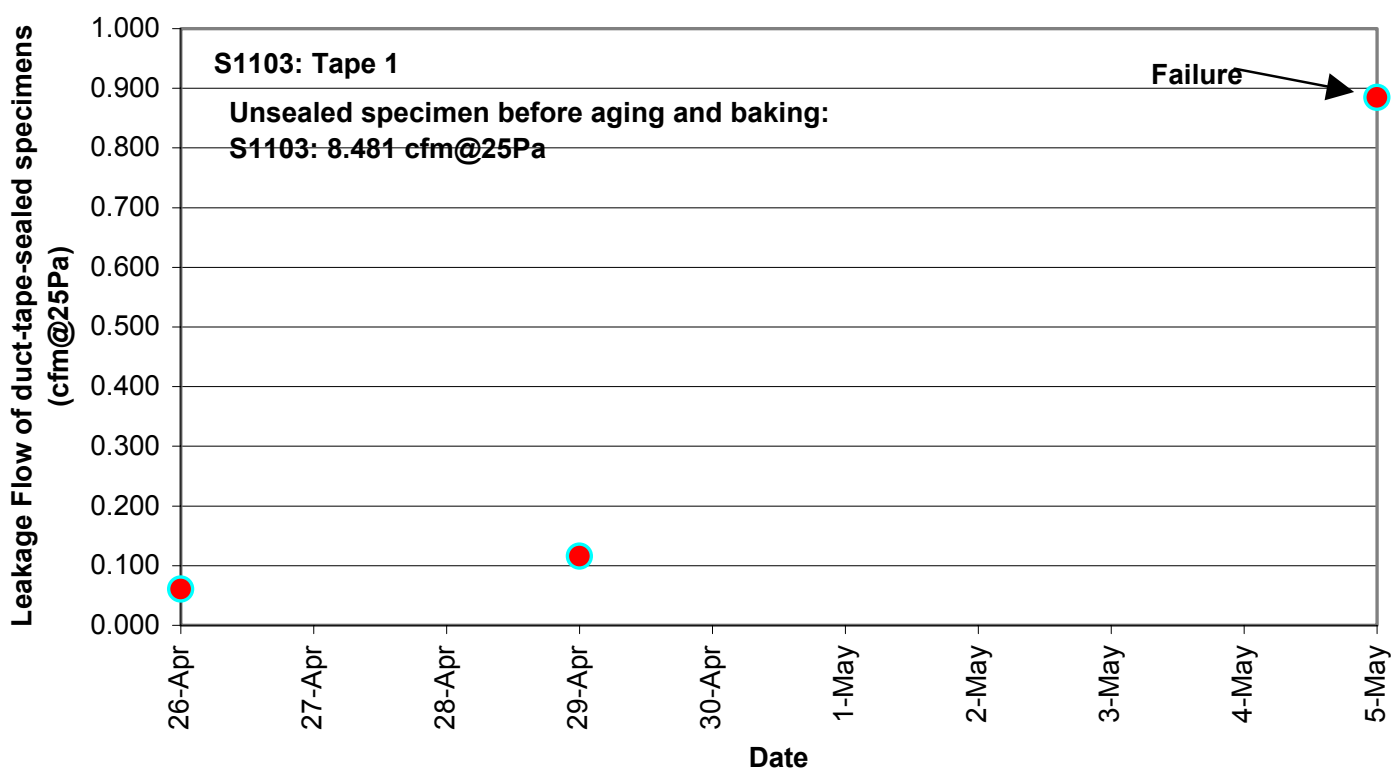

Figure 15. The measured leakage of the collar-to-plenum joint Tape-1 specimen.

Table 4. Failure Results of the Collar-to-Plenum Joint Specimens in the Aging Test.

\begin{tabular}{|c|c|c|c|}
\hline \multirow{2}{*}{ Tape } & Specimen & $\begin{array}{c}\text { Temperature } \\
\text { F }\left({ }^{\circ} \mathrm{C}\right)\end{array}$ & Elapsed Time Before Failure \\
\hline \multirow{4}{*}{5} & S1100 & $111(44)$ & No Failure after 4 Months and 3 Weeks \\
\cline { 2 - 4 } & $\mathrm{S} 1101$ & $147(64)$ & 4 Months and 3 Weeks \\
\cline { 2 - 4 } & $\mathrm{S} 1102$ & $194(90)$ & 2 Months and 2 Weeks \\
\cline { 2 - 4 } & $\mathrm{S} 1105$ & $194(90)$ & 1 Month and 3 Weeks \\
\hline 1 & $\mathrm{~S} 1103$ & $194(90)$ & 9 Days \\
\hline
\end{tabular}

Figure 16 shows the failure of the 3-D joint as the duct tape tends to pull away from the sheet metal, thus uncovering the series of overlapping fin-joints. 


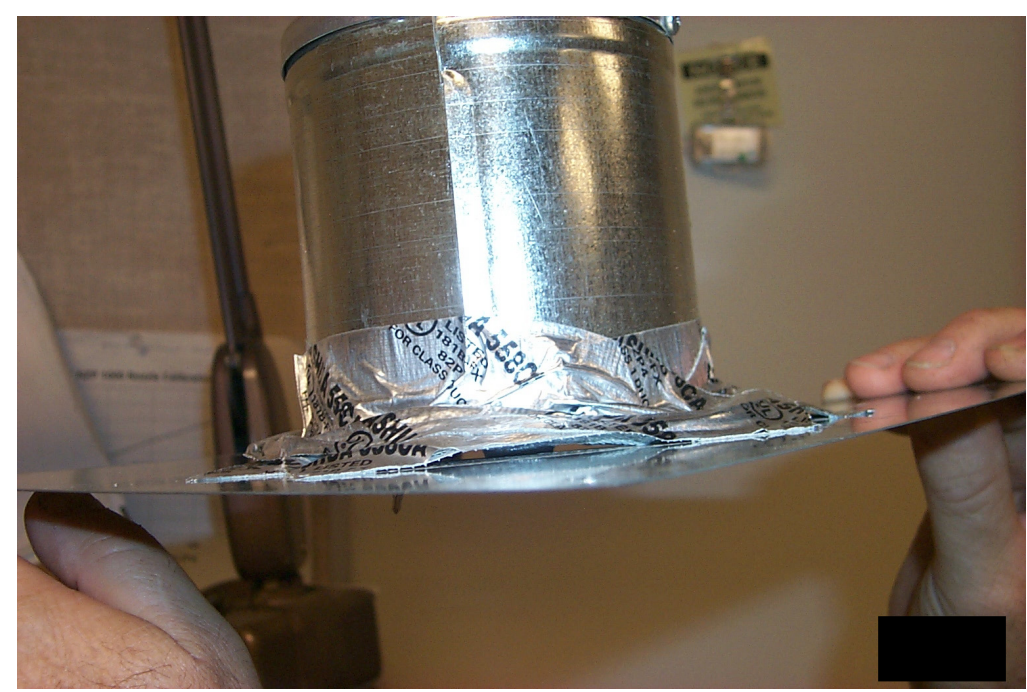

Figure 16. A typical failure of the 3-D collar-to-plenum joint.

Baking test. Visual inspection of the baking specimens showed gradual deterioration in the specimens over the 60 days period of the test (as required by the UL standard), whereas specimens of the duct tape tested which were hung in the oven without being applied to any substrate showed considerable deterioration after only two weeks of baking.

After the first week of baking, the specimens showed the following:

- No significant deterioration among all specimens.

- No noticeable shrinkage of the tape on the sheet metal substrates.

- The Aluminum Foil and PET specimens tended to roll (curl).

- The hanging specimens tended to "curl" as well.

- The Polyethylene specimens did not show any rolling; their surface in fact became "rougher" (the polyurethane used is a "woven film").

The rolling in most cases was a result of shrinkage in the duct tape that allows it to deform the substrate with it as it shrinks. In the case of the polyethylene substrates, the substrate itself showed some shrinkage after the second week of baking.

The specimens were inspected weekly. When the test was completed after the 60-day period, the final observations of the visual inspection were recorded and summarized. Table 5 shows these final observations, and, similar to Table 3 , assigns points ( 0 to 2$)$ to each of the ten features of the degradation; " 0 " denoting either "no sign of deterioration" in that category (feature), " 1 " denoting a "moderate deterioration", and " 2 " denoting an "excessive deterioration". The table also includes the total number of points given to each specimen. 


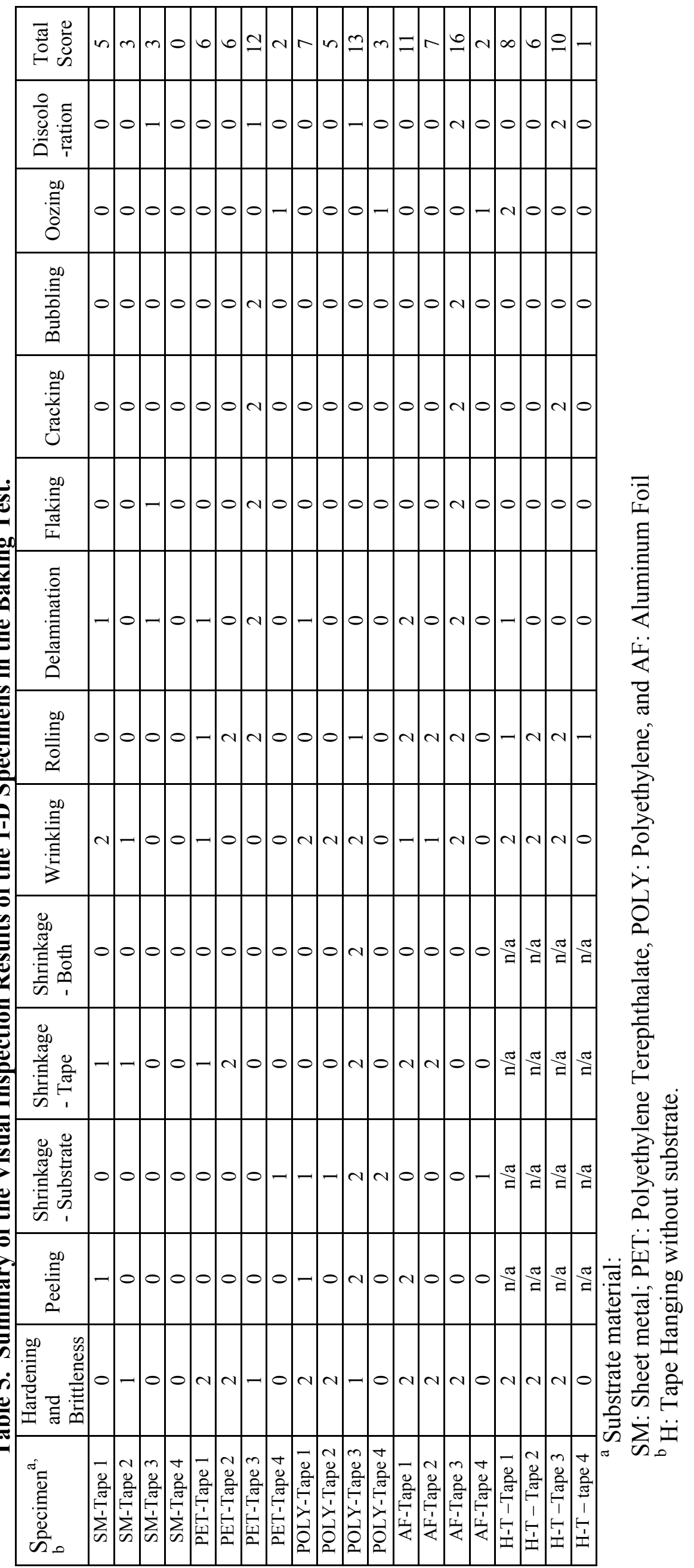


As can be seen in Table 5, the Tape 4 specimens (foil-butyl tape) showed the least deterioration, while its combination with the sheet metal (SM) substrate shows no deterioration at all. The Tape 3 specimens (film tape) showed the most deterioration. Its combination with the aluminum foil (AF) substrate was the worst case. Also, in agreement with the aging test results of the conventional duct tape (Tape 1 and Tape 2), Tape 2 showed a better performance than Tape 1 .

The results for the hanging specimens were consistent with those of the substrate combinations. The tapes were ranked from worst to best as follows: Tape 4; Tape 2; Tape 1; Tape 3.

\section{Conclusion}

The aging tests conducted so far showed that duct tape tends to degrade in its performance as the joint it is applied to requires a geometrical description of a higher number of space dimensions (1-D, 2-D, 3-D). One-dimensional joints are the easiest to seal with duct tape, and thus the least to experience failure. Two-dimensional joints, such as the flexible duct core-to-collar joints tested in this study, are less likely to fail than three-dimensional collar-to-plenum joints, as the shrinkage could have a positive effect in tightening the joint. Three-dimensional joints are the toughest to seal and the most likely to experience failure.

The 2-D flexible duct core-to-collar joints passed the six-month period of the aging test in terms of leakage, but with the exception of the foil-butyl tape, showed degradation in terms hardening, brittleness, partial peeling, shrinkage, wrinkling, delamination of the tape layers, flaking, cracking, bubbling, oozing and discoloration.

The baking test results showed that the failure in the duct tape joints could be attributed to the type of combination of the duct tape and the material it is applied to, as the duct tape behaves differently with different substrates.

Overall, the foil-butyl tape (Tape 4) had the best results, while the film tape (Tape 3) showed the most deterioration. The conventional duct tapes tested (Tape 1 and Tape 2) were between these two extremes, with Tape 2 performing better than Tape 1 .

Lastly, we found that plastic straps became discolored and brittle during the tests, and a couple of straps broke completely. Therefore, we recommend that clamping the ducttaped flexible core-to-collar joints should be done with metallic adjustable straps.

\section{Future Work}

Future work on baking tests of duct tape will involve the same substrate materials used in this study, but of greater thickness. This will prevent the curling of the substrates together with the tapes and represent a situation more like the real life application of the tapes.

Duct tape is sensitive to dust and oil covered surfaces, which could reduce its adherence significantly. In field installations, sheet metal fittings are usually not cleaned with 
chemical solutions to remove dust and oil. In the future work we plan to design of a systematic test to characterize and quantify the effect of dirt and oil residues (normally found on sheet metal fittings) on the longevity of duct tape sealed joints.

\section{Acknowledgements}

This report describes work supported by the California Energy Commission through the Public Interest Energy Research program under contract no. 500-98-033, and by the Assistant Secretary for Energy Efficiency and Renewable Energy, Office of Building Technology, State and Community Programs, Office of Building Research and Standards, of the U.S. Department of Energy under contract no. DE-AC03-76SF00098. The author also wishes to acknowledge the contribution of Darryl Dickerhoff through discussions on developing the test equipment and specimens.

\section{References}

Sherman, M.H., Walker, I.S. and Dickerhoff, D.J. 2000. "Stopping Duct Quacks: Longevity of Residential Duct Sealants". Proc. ACEEE 2000 Summer Study. Vol. 1, pp. 273-284. American Council for an Energy Efficient Economy, Washington, D.C. (LBNL 45423)

Sherman, M.H. and Walker, I.S. 1998. "Can Duct Tape Take the Heat?", Home Energy Magazine, Vol. 14, No. 4, pp.14-19, July/August 1998, Berkeley, CA. LBNL 41434.

Underwriters Laboratory (UL). 1993. Standard for Closure Systems for Use with Rigid Air Ducts and Air Connectors - UL 181A. Underwriters Laboratories Inc. Northbrook, IL.

Underwriters Laboratory (UL). 1995. Standard for Closure Systems for Use with Flexible Air Ducts and Air Connectors - UL 181B. Underwriters Laboratories Inc. Northbrook, IL.

Walker, I., Sherman, M., Modera, M., and Siegel, J. 1998. Leakage Diagnostics, Sealant Longevity, Sizing and Technology Transfer in Residential Thermal Distribution Systems. LBNL-41118, Lawrence Berkeley National Laboratory, Berkeley, CA.

Walker, I., Sherman, M., Siegel, J., Wang, D., Buchanan, C., and Modera, M. 1999. Leakage Diagnostics, Sealant Longevity, Sizing and Technology Transfer in Residential Thermal Distribution Systems: Part II - Residential Thermal Distribution Systems Phase VI Final Report. LBNL-42691, Lawrence Berkeley National Laboratory, Berkeley, CA.

Walker, I.S., and Sherman, M.H. 2000. "Assessing the Longevity of Residential Duct Sealants", Proc. RILEM ${ }^{\text {rd }}$ International Symposium: Durability of Building and Construction Sealants, February 2000. pp. 71-86. RILEM Publications, Paris, France. (LBNL 43381). 